\title{
Mariana Acuña-Acosta, VFX artist
}

Mariana Acuña-Acosta has worked in the film industry for more than fifteen years, both in Mexico and the United States, contributing to such notable projects as Lost (2004-10) and Green Lantern (2011). Besides her VFX credits, she has also trained VFX artists in the latest technologies and served as a consultant to shop managers around the world. Here she discusses the tyranny of iterative VFX work, gender dynamics in the workplace, and the challenges confronting labor activists in the effects industry.

How did you get started in the business?

When I was little I saw the movie Young Sherlock Holmes (1985). It had a lot of visual effects and I loved it. One day, I actually went to see it five times. I knew that that was what I wanted to do. I just didn't know how. Then in college I wanted to study something artistic and a new major came up, a bachelor of fine arts in new media, which was 3D animation, video art, net art, programming, and scripting. I thought, wow, this is the future. This is where it's all going.

What school did you attend?

It's called Universidad de las Américas Puebla. Before, it used to be called the American College. It's in a town called Puebla, three hours away from Mexico City. 
Why did they start the program?

Back then everyone was trying to make websites, and use email and the Internet in universities. They saw that this had a lot of potential. At the same time, there were exhibits of Internet art and digital art. They were very progressive at that school. I was the only woman in this major and there were only eight of us in total: seven guys and me. We started doing short films together and putting them in film festivals. We also saw that there was a market for it, so we put together a visual effects studio. We would make corporate videos and do digital effects for wedding videos.

After I graduate, a visual artist in New York hires me, so I move to New York and I'm super excited. I just graduated and I'm living in SoHo. I'm thinking, wow, this is a dream come true. I had these amazing computers and I would do all the visual and audio effects for this artist who was exhibiting at the Guggenheim and galleries in Chelsea or wherever. The only problem was that I didn't have any days off. I was working every day from ten in the morning to one in the morning. She didn't think I was allowed to have a day off because I was living in SoHo and that should be payment enough. She paid for all my living expenses in New York in exchange for my work, and that was it. After a year, I got tired of it. It was like living in a golden cage.

Is that even legal?

No, it's not legal. I didn't know. I was young. Obviously I was so excited to be living in New York with this visual artist that I didn't realize the position I had put myself in.

\section{Did you get credit for your work?}

No. She didn't want people to know that she didn't actually know how to do all of this. She was friends with one of my teachers in college, who introduced us. I don't regret it, because it was a great experience, but throughout my career I've seen the same sorts of behavior. People take advantage of your willingness to do whatever it takes to do something you love in the visual arts.

After New York you moved back to Mexico, but you decided to move to Mexico City instead of Puebla.

Puebla was great for going to college but work-wise there was nothing I could have done there. So I went to Mexico City and I kept doing my short films and putting them into film festivals. Then I got a job working in production on American films like Troy (2004), The Day After Tomorrow (2004), and Nacho Libre (2006). There were all these movies being shot in Mexico back then, so I started working on set as an assistant, which was awesome. The pay was good and we had per diems. All that was fantastic. I did that for a few years. 
In one of the last movies on I worked on, which was Troy, I became very good friends with all the visual effects people. I thought, oh, wow, you can do this for a living. So I went to Spain and did a master's degree in new technologies and postproduction. I was there for two years. I did film festivals and a lot of other things, like interactive design. Then I realized I needed something even more specialized, so when I won some money from one of my short animated films, I came to L.A. to study at the Gnomon School of Visual Effects. After that, I got my first job as a compositor, which is what I've been doing ever since. When I went back to Mexico, the day after I arrived, I went to the biggest movie studio and I had a job on Monday.

\section{What was it like to work for the studio in Mexico City?}

At the beginning, I thought it was really cool, because we had valet parking, free coffee, and good food, but realistically, the pay sucked and because we were hired as freelancers, we didn't get any of the staff benefits like health insurance, pension, or sick days. We had all the responsibilities of being a staff employee, but were hired as freelancers.

\section{Was this a Mexico City studio or a division of a Hollywood studio?}

It was a studio in Mexico City, but it handled a lot of overflow work from shops in Hollywood. Oddly enough, I thought it was because we did such fantastic work. Later I found out, no, it's because our studio would underbid all of the studios in L.A. Obviously when you're bidding in Mexican pesos you have an edge. The same was true with working conditions because there are no labor laws in Mexico. The owner could make so much money from one shot that at the end of the day, he could pay all our salaries. The overhead was not that high, so he could underbid everyone in the US. That's why we ended up getting all that overflow work.

\section{How big was the shop?}

The studio was pretty big, but the visual effects division was only five people.

What were the other parts of the studio?

They produced films, programs, and commercials. They also acted as an advertising agency. And they provided services for Hollywood productions-lab services like scanning the film and then turning it into data and then doing some of the data wrangling. They also did color conversions. And a lot of motion graphics for television commercials. That division generated a lot of work, but the people who worked there were treated like we were. 
How many people were working at this studio?

I would say 150.

That's pretty big. And your group focused on VFX for feature films?

Yes. Between the five of us, we did one movie that had more than four hundred visual effects shots. We worked for three months straight and didn't have one day off.

There seems to be a pattern here.

Exactly.

What was a typical workday like?

It was probably ten in the morning to maybe midnight or one in the morning, seven days a week.

How long did you work there?

For two years. Until I got sick of the working conditions.

What were some of the other challenges when you were working there?

They started to eliminate the perks that we used to think were great. Suddenly we didn't have a valet service. Parking in Mexico City is a pain in the butt because it's so crowded, so basically there was nowhere to park, and they were like, yeah, we don't care. We're reducing costs. They fired all the valet parking people on Christmas Day, I remember that specifically. Then they stopped providing free coffee and closed the cafeteria. They wouldn't raise our salaries at all. Basically they didn't want to do anything for us. At the end, they roped us into a group health insurance plan that we all paid for, but that was so they could get a tax break for it. If you complained, they'd say, there are a lot of people who want to do this, so if you don't, there's the door.

Were you paid hourly or weekly?

Biweekly. A flat rate, no matter how many hours you worked.

Compared to other professions in Mexico City, was it a good wage?

No. I was making way more as a production assistant on Hollywood movies in Mexico. 


\section{How much more?}

About 35 percent.

Was the studio in bad shape financially?

No, no, no. The owners had a lot of money. All this was just so they could make more money. They also pirated all their software. Nothing was legal. They didn't care. One of the owners was this super-privileged rich guy. His parents were European and owned hotels around the world. They didn't care about the human component at all. This shop could have been fantastic, outstanding. It had a great group of employees. It could have been an example of a good company, but they didn't care about the workers.

And it wasn't just the studio owners in Mexico; the Hollywood executives knew what was going on. They knew why they were getting a deal, and they knew about the pirated software. I can send you an article about this shop in Spain where everything is being done illegally, and all the studios know about it. As long as they make their money, they don't care what's going on at the other end. The same thing is going on right now in India, those poor guys are doing all this rotoscoping work under terrible conditions. But does anybody care? No.

What can you tell us about those conditions?

At some of the shops the worker has to pay the company a bonus because the employer says it is giving them a chance to work on a Hollywood movie. These are horrible places where people are working side by side, with bad equipment and terrible hours. VFX Soldier has posted a lot of detailed stories on the conditions for the Indian workers. VFX workers are not treated as artists. They have become human commodities.

Can you elaborate? Why human commodities?

Many films today will have 2,500 shots in them. That's a lot of work for a lot of people. At the end of the day, it doesn't matter what brand it is or who is producing it, as long as it gets produced.

\section{Back to Mexico City...}

In the spring of 2008, I realized the industry was not that strong in Mexico and I would never be able to expand my knowledge or learn more from the people around me. I knew more than post-producers and supervisors, so I thought to 
myself, okay, I need to move or I am never going to make any money. If I want better working conditions and a better salary, and if I want to make this a career, I need to move. So in January 2009, I moved to L.A.

How would you compare the working conditions in Los Angeles to those in Mexico City?

In Los Angeles, I started getting paid a reasonable hourly wage, even enough to save some money. And they actually will pay you, no shenanigans. And the more you know, the more you can earn. Still, it was a big surprise to me that there was no health insurance, you didn't have a $401 \mathrm{k}$, and you still had crazy hours. I thought it would be a normal job, but it's the same crazy hours. The pay is definitely better. You can't even compare. Here you get paid hourly and you get overtime, and double overtime on the weekends or if you have to work on a holiday. That would have never happened in Mexico. The problem is that it's hard to keep a job. It's crazy to think that I moved here in 2009 and five of the places where I worked have gone under, bankrupt. I have been offered jobs in Vancouver and in London, but I don't want to move. I have already moved to a lot of places. But that's what many people feel they have to do.

We want to talk about the artistry of visual effects, so let's zero in on a scene you worked on from the very end of the film Surrogates (2009), starring Bruce Willis. Most of the time when we think of visual effects we think of dinosaurs, space travel, or spectacular explosions, but this one is short and seemingly simple. In it, we see a soldier at a computer screen that flashes "Surrogate disabled." Then the shot widens to include Colonel Brendon striding into the command room, grabbing a clipboard, and turning to FBI agents Tom Greer, played by Bruce Willis, and Jennifer Peters, played by Radha Mitchell.

The reason to talk about this shot is not because it was my most challenging work or my favorite shot or the shot that made me rich or anything like that. Instead, it's because this shot was given to me the first day I started working in L.A. It was also the last shot I worked on in that particular movie, even though I finished more than twenty shots overall. It was a nightmare because I ended up doing ninetyseven versions, but there was no extra compensation for all the work I did. The shot was just part of the workload that my company was responsible for once it signed a fixed-bid contract with Disney.

In this particular shot, all of Bruce Willis from the nose down is a 3D model. I had a production sheet from the studio that told me what to do to his head, like put more hair on it-that was because Bruce Willis decided during the filming to cut his wig, which didn't go over well. Then the nose: they didn't like the way his nose 
was shaped, so I had to reconfigure the nose. Then the forehead had to be reconfigured as well. Then I had to remove or soften his nasal labial fold. I had to make his cheekbones more pronounced so he could look more manly. That was actually on the notes: "make him more manly." I had to reshape the inside of his nose and reconfigure his nostrils. I also had to push back part of his mouth and make his lips plumper. Then I had to reconfigure his sideburns to make his earlobes prettier. Yes, prettier earlobes. Nothing that you see in the movies or in commercials is natural. Nothing is real. Nothing is real at all.

They also wanted me to change Jennifer's face. I kept saying, she looks pretty. They said no, make her look younger. They kept asking me to change her. I decided they're never going to look back at previous versions so I started telling them, yes, I softened up her cheekbones, or, I softened up her features. They said, "Oh, yes, she looks great.” I actually did nothing on her.

Every time I got notes from the studio, I had to do another version. Ninetyseven versions of this shot, in total. It was relentless: add more hair, make less hair, put the hair up, put the hair down, make the cheekbones smaller, make the cheekbones more concave, make the cheekbones stand out, make him blush more, no that's too much blush, plump his lips more, now plump them less. Make his ear smaller, make his ear bigger, make it more manly-whatever that means. Jesus Christ, it was never-ending.

The managers in our office would do Friday cupcakes or throw a farewell party for someone, and everybody would gather together except me. "Ah, Mariana is busy doing version eighty-seven, eighty-eight." It was like a joke. Then at some point the studio people said, "It's not you. It's just that we don't like Bruce Willis's face."

Ninety-seven versions? Who in their right mind would order ninety-seven? If you were shooting principal photography and someone asked for ninety-seven shots, it would cost a bundle. The meter would be running.

Of course. I think that's one of the most unfortunate problems for the VFX industry. There is so much artistry going on behind the scenes after the filming is over. And it's invisible to the eye. Unfortunately, directors, producers, coordinators, people at the studios at the very top don't understand what VFX entails because-

- many of them won't even come into the shop.

Exactly. They think a computer does the work-that you just click a button and it's done. They don't know what it takes.

Once when I was working as a PA [production assistant] on set, it was a night shoot and one of the focus pullers was tired and didn't realize that the shot had gone out of focus. They finished up their work on that scene and then they broke 
down the set. The following day in dailies they realized that the whole scene was out of focus and it was a million-dollar mistake because they had to rebuild the set and reshoot the scene. It was just insanity and a very costly mistake, right?

Well, that happens with visual effects, but the directors and the studio executives don't realize it. If on a movie set, a director doesn't like the look of the set and says, "Let's change it, let's do Art Deco, everything is going to be orange and three stories higher, and we're just going to move the whole set over here and do a week of night shots," people will say, "You're crazy. That's not happening because it's going to cost too much money." This is what happens during principal photography because the meter is running.

\section{And it's all unionized labor.}

It's all unionized labor and you're on the clock. So if you're going to change the set, you have to rebuild the set. You've got a whole bunch of people working on it hour by hour and it's all costing you extra money.

Another reason the studios can make demands on VFX shops is because of the competition and the fixed bidding system. You're not just bidding against Digital Domain, Rhythm \& Hues, and the other shops in L.A., but also against shops in other parts of the world. Some of those shops are very specialized with very low overhead. They will be doing wire removal or rotoscoping or whatever, each of which requires different levels of skill and craft. In a way, it's like the fashion industry where people in one shop are sewing on buttons and in another they're assembling pieces of garments and in another they're doing fashion design. All these people are spread around the globe now. Part of that has to do with government subsidies, but part has to do with the fact that you can communicate electronically and you can fly people around the world.

Let's look at this issue from a policy perspective. If we were government officials in Mexico City, it would be our responsibility to create new jobs, especially skilled jobs that pay well and don't pollute. We'd want to build capacity so that Mexico City's VFX companies could compete with others around the world. If subsidies help us do that, what's wrong with it?

From their perspective it seems to make sense, but there's also a lot of exploitation. There are so many people in Mexico City aspiring to these kinds of jobs that the schools can't keep up with demand. So some shops lure young people in with, "You're going to work in Hollywood someday, so work for us for free." You get a lot of students who are working for free in the shops in Mexico City. As for government subsidies, it's the owners who get these rebates. They do some deals with producers and of course for them it's great. I mean, why wouldn't they? It's free money. 
Could you speak about your experience as a woman working in an industry largely dominated by men?

It's funny because in Mexico we were mostly women, so I assumed when I moved to L.A. that it was going to be the same. But in my first job, Surrogates, I was the only woman for quite a while, among twenty or so men. I was surprised.

You have an interesting perspective on this issue, since, as a software trainer at Foundry, you now travel around to a lot of different VFX facilities.

Yes, I've done training in places like Pixar and Rainmaker. At Pixar I was training forty men and I was the only woman in the room. This was in visual effects. In compositing you'll find a few more women; 3D animators, maybe a little bit more; but lighting and effects and cloth simulation, no.

There are two reasons why it's so male dominated. One is that it's our problem. We women think that men are more technical. I once read that until age four we're exactly the same and then from four on up, it changes: your parents and TV and all these things have an effect. Your parents may give you a little iron or a dress instead of a video game. They don't tell you that you can do computer programming, that's more for your brother. You're supposed to do other things. But not me, I actually loved video games and programming, and my mom was good with all that. I was lucky. Most women come to believe they're not as technical or as talented as men-that they can't, for example, do cloth simulation effects. I've noticed that more and more.

All the VFX tutorials that you see online are done by men. Whatever the software, it doesn't matter. I got pretty tired of that, so I said, "I'm going to do a YouTube channel. It's going to be called VFX Chicks and I'm going to grab matte painters and lighters; I'm going to put together a whole crew of women and I'm going to put them on screen." I actually raised the money for it. I had a camera and a crew. I had the list of the women I was going to approach: fifteen of them, aged twentyfour to fifty-five. We were going to post a tutorial every month: matte painting, compositing, lighting, et cetera. And I was going to pay them, so it wouldn't be for free. It was going to start with a two-minute interview, because you never see faces in the tutorials, but now people are going to see that they're cute, and they'll stay and watch the rest.

I was ready to go. How many of the fifteen women accepted? None. What answers did I get? "I'm going to look fat on camera. I'm going to look ugly." So I said, "Let's skip the two-minute interview at the beginning and go straight into the tutorial." "No, I'm not technical. I've never done a tutorial. I can't talk in front of a camera." "But you're not going to be looking at the camera. It's a recording of the software you use." Still, none of them accepted and they all gave me awful answers, 
not believing in themselves. Women lack confidence and men are overconfident. It's sad.

Another reason the industry is male dominated has to do with family responsibilities. Let's say you're in your twenties and you get into the industry because you've seen really talented young women between the ages twenty-one and thirty-two. Maybe they're driven and willing to do whatever it takes. But then, what happens? At thirty, you get the baby-craze hormones. You want to have a family and maybe you get married. Then you realize that you're working in an industry with no maternity leave and no one is going to pay your hospital bills. And then there's your work schedule. In every job I've had, you work six to seven days a week, twelve- to fourteen-hour days. If you tell them you're going to work parttime because you're having a baby, they're going to go find someone else. When I was pregnant, I worked in a shop that was very nice: they let me work elevenhour days instead of twelve, and six-day weeks instead of seven. That's as good as it gets.

True story: One of my friends in Mexico City had a baby, and she brings her baby to the visual effects shop. The baby has a crib there and my friend says, "They're very nice because they let me bring the baby to work." And I'm like, are you insane? She says, "They let me breast-feed in the bathroom." Oh, how nice they let you do that!

A lot of women start in this industry when they're young. They're not thinking about a family or getting married or anything else. But then when you have a baby, you realize the working conditions are not making it easy. So you end up changing industries or becoming a stay-at-home mom and then going back to work later, because most shops are not going to make adjustments.

Do you see the same sorts of gender dynamics in the shops you visit outside the United States?

In the US it's white males between the ages of twenty-two and thirty-five. Obviously you will find producers and VFX supervisors who are in their forties, fifties, and sixties, but for the most part, the artists are going to be young white males. As for the shops I've seen around the world, in Vancouver there are lots of Mexicans and lots of Europeans because they can't find enough people locally. Australian shops also have a lot of Europeans, but again, they are all male and from a certain age group. You hardly see any African Americans. I've never seen an African American woman, for example, and maybe two African American guys. I've never seen an African American supervisor and there are hardly any women who are supervisors or leads. They will always go for a man and they will always go for a white man. Of course, when I started out, I thought there would be more women, but it's a boys' club. And obviously that creates a workplace dynamic that is not 
comfortable for women. But the same sort of thing happens whenever you work in a place where everyone comes from the same background. It's like a fraternity.

\section{Tell us what you're doing now for Foundry.}

I wear multiple hats. I create demo materials for trade shows like NAB and SIGRAPH. I create training videos. I also do customized trainings for studios like Pixar or Blizzard or Rainmaker. I reach out to universities and training facilities in multiple locations like San Francisco, Mexico, Brazil, Portland, Australia, and Vancouver. I talk about the industry and show them the tools, and also go to studios around the world showing them new features and new workloads, gathering feedback, doing technical talks. I also have to be on the forefront of what's going on with technology. For example, now I'm gathering feedback from all the shops about issues that are arising with virtual reality.

That's an amazing list of responsibilities. It sounds like you have the opportunity to peek into many different work environments. Do you think your perspective on the business has changed since you've been doing this job? Have you seen trends emerging that you think are remarkable?

I feel very privileged that I get to see all these different studios around the world and see what the working conditions are like, because it interests me a lot. At the same time, this whole gender issue stands out-whether you're in Australia, New Zealand, Canada, or London. It feels like a sexist and ageist industry. It burns people out. As you become older it's like, man, I'm tired of this. I need to have a job that is going to last more than three months. As you grow older, obviously you want a better pay rate and you're more concerned about benefits, especially health insurance. When you're younger you don't think about those things and you're willing to do whatever it takes to get your foot in the door, whether that's working for free or working seven days a week. Worldwide, it's very ageist and very sexist. I keep seeing the exact same dynamics over and over again. Women get passed over for leadership positions. Sure, they are great for marketing or coordinating or HR but not for the creative, technical, or decision-making positions. A woman would never even be sought for a position like that. That's the same across the globe.

Have you seen a shop that has done a good job of overcoming that gender dynamic? Are there shops where they have made it a priority to incorporate the creative energies of women?

Yes. It can be done. I can think of three different shops here in L.A. where they make it a point to hire more women and get women in technical roles. 
What are the three shops?

One of them is Sony Pictures Imageworks, another is Ingenuity Studios, and then there's Luma Pictures, which is based in Australia and also here in Los Angeles. It can be done if there's a commitment to doing it.

Let's talk about labor organizing among VFX artists. Given what you've described, why haven't people formed a union?

I remember I used to think, "At least I'm going to get my name in the credits." But even so, VFX workers are treated differently. When you work on a film set and you're unionized, your name has to go in the credits. Not so for VFX. The reason why the visual effects credits come after the people who pick up the trash-no offense to them, they do a great job-but the reason we come all the way at the end is because we don't have a union. So guess what? If the producer says, "We ran out of roll and so we'll cut out the three hundred VFX credits," it's not like anybody cares. Who are you going to turn to because your name isn't on the credits?

People are finally talking and they're organizing. They're talking not only in Hollywood, but around the world. So the way to think about this is that a lot has changed over the past five years and it can get better, but people have to commit. VFX can be a wonderful industry to work in. We just need to change it. 